\title{
A Three Month-Old Girl with Cleft (Bifid) Sternum and Hemangioma of the Face
}

\author{
Behzad Mohammadpour Ahranjani (Di] ${ }^{1,}$, , Maryam Qodsi ${ }^{1}$ and Armen Malekian Taghi ${ }^{1}$ \\ ${ }^{1}$ Tehran University of Medical Sciences, Tehran, Iran \\ "Corresponding author: Tehran University of Medical Sciences, Tehran, Iran. Email: behzadpediatr@yahoo.com
}

Received 2018 September 30; Revised 2018 December 24; Accepted 2018 December 29.

\begin{abstract}
Cleft sternum is a rare congenital malformation of the chest cavity. The failure of embryologic fusion of mescenchymal cells in the midline causes the amomaly, leaving the mediastinal viscera exposed to injuries. The defect is usually divided into partial or complete forms and is often accompanied by other anomalies. The etiology and incidence are not yet known. We present a case of bifid sternum with hemangioma of the face.
\end{abstract}

Keywords: Sternal Defects, Hemangiomas, Chest Cavity

\section{Introduction}

During the embryologic development, the body of the sternum arises from migrating cells originating in the lateral mesoderm plate, which forms two bands that fuse by the 10th week of gestation. The manubrium arises from primordia between the ventral ends of the clavicles. Failure of the fusion leads to cleft sternum. The first case of sternum bifidum was reported in 1739 by De Torres (1).

The spectrum of sternal deformities has been classified by the group from Boston Children's Hospital (2). Thoracic ectopia cordis (complete cleft), or so-called naked heart, involves a cleft sternal in which there are no overlying somatic structures and the heart is exposed. This type is believed to be the result of disruption of the amnion, chorion, or yolk sac during embryologic development (3). The apex of the heart is characteristically positioned anteriorly and cephalad. Intrinsic cardiac anomalies are frequent, and this deformity is often fatal.

Cervical ectopia cordis (upper sternal defect) is a more severe form of this defect involving a more superior displacement of the apex of the heart, often with a fusion of the apex of the heart to the mouth. The prognosis in these patients is dismal, but fortunately this defect is extremely rare (4).

Thoracoabdominal ectopia cordis (sistal sternal cleft) is the most extensive defect and associated with Cantrell's Pentalogy. This group of anomalies is characterized by a distal cleft in the sternum, omphalocele, diaphragmatic cleft, pericardial and congenital heart defects with the lat- ter including ventricular septal defect, tetralogy of Fallot, etc.

Cleft sternum (sternum bifidum) is the least severe anomaly of the sternum and may be associated with facial hemangiomas. Only the sternum is involved in this variant; there is an intact pericardium and normal skin coverage over the defect. Abdominal wall defects are not present, nor are intracardiac defects (5).

\section{Case Presentation}

We present a three-month old girl infant who had been refered for the treatment of the facial hemangioma. She was born by cesarean section with no complication other than the hemangioma and sternal cleft. On inspection she had an easily seen hemangioma at the left lower side of the face spreading onto the upper neck and an obvious retraction in the middle of the chest proving a defect in the bone of the sternum. The neurodevelopment milestones seemed normal. The skin of the chest cavity was intact and the physical examination of the heart and lungs were normal. A deep concavity representing the bifid sternum was clearly seen in the middle of the chest, and a vascular abnormality, the hemangioma, was detected onto the lower face (Figure 1). Also, a midline abdominal raphe was seen on the superior abdomen although no diastasis recti was found (Figure 1). Otherwise the physical examination was normal. 


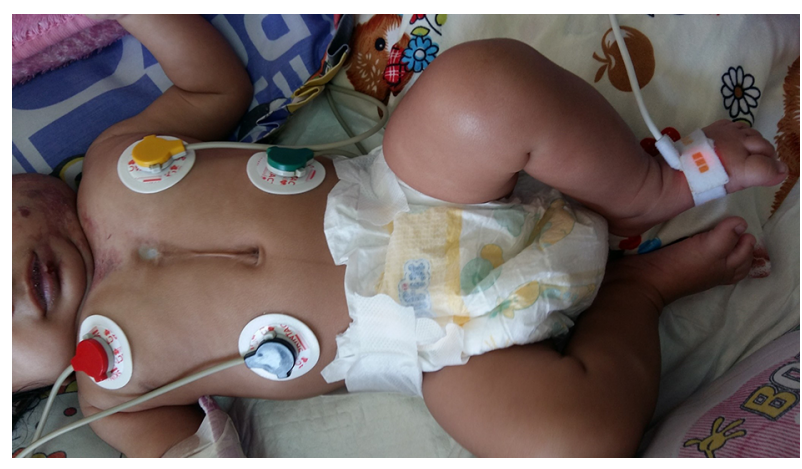

Figure 1. The bifid sternum

The sonography of the abdomen was normal and nothing abnormal was found in the brain MRI. The echocardiography demonstrated a patent foramen ovale. Also the ECG was normal. No significant finding was detected on the chest X-ray. The vital signs, except for the retraction, and SPo2 were normal. Our final diagnosis for this patient was "bifid sternum". Propranolol was started for the hemangioma and a surgical repair was scheduled for the cleft sternum and hemangioma, just in case, if the latter would not disappear after the medical treatment.

\section{Discussion}

The method and time of the surgical repair of such sternal defects is actually the hard point and most challenging aspect of the correction process. Early repair is essential to easy approximation of bars so as to rebuild bony protection to the mediastinal structures and to provide normal intrathoracic pressure relationships. Therefore it is quite obvious that age of the patient should be considered as a major factor for determining the technique of sergical correction. The younger the patient, the more flexible is the chest cavity and as a result the success rate of a primary direct closure will be more.

Another aspect of the problem that always needs to be kept in mind is the presence of other congenital anomalies which in turn makes the situation much more complicated.

The first report of a successful surgical cleft sternum in an eleven-week old child was published in 1947 by Burton (6). Because of the high flexibility of the chest wall of newborns, the primary closure is easier to perform and the risk for cardiovascular impairment is decreased (7). If the patient presents later in life, reconstruction surgery is required because a simple approximation is impossible due to increasing rigidity of the chest wall and difficulting in accomodating the heart and lungs within the chest cavity (8).

Our case was the most simple among other types of sternal clefts. The accompanied anomaly was a facial hemangioma making no risk for the patient at the time of presentation and needed just a medical treatment so as to be resolved and a routine follow-up to check the effect of the medication prescribed. As for the sternal cleft, although the patient was referred to our center after the neonatal period, since it was a bifid sternum, still she had the chance to go through surgical closure and most probably a perfect repair.

The last thing that needs to be emphasized is that early diagnosis and surgery of such patients is the key point to give them not only survival but also a good quality of life.

\section{Footnotes}

Confllict of Interests: The authors declare no conflict of interests.

Funding/Support: There was no funding for the case report.

Patient Consent: The patient consent had been taken.

\section{References}

1. De Torres JI. Extract of a letter from Jos. Ignat. De Torres, MD to the Royal Society, containing an extraordinary case of the heart of a child turned upside down. Philos T (1683-1775). 1739;41:776-8. doi: 10.1098/rstl.1739.0137.

2. Shamberger RC, Welch KJ. Sternal defects. Pediatr Surg Int. 1990;5(3):156-64. doi: 10.1007/BF00179653.

3. Kaplan LC, Matsuoka R, Gilbert EF, Opitz JM, Kurnit DM. Ectopia cordis and cleft sternum: Evidence for mechanical teratogenesis following rupture of the chorion or yolk sac. Am J Med Genet. 1985;21(1):187-202. doi:10.1002/ajmg.1320210128. [PubMed: 4003443].

4. Sabiston DJ. The surgical management of congenital bifid sternum with partial ectopia cordis. J Thorac Surg. 1958;35(1):118-22. [PubMed: 13514809].

5. Cantrell JR, Haller JA, Ravitch MM. A syndrome of congenital defects involving the abdominal wall, sternum, diaphragm, pericardium, and heart. Surg Gynecol Obstet.1958;107(5):602-14. [PubMed: 13592660].

6. Burton JF. Method of correction of ectopia cordis. Arch Surg. 1947;54(1):79-84. [PubMed: 20286080].

7. Singh S, Lahoti BK, Garge S, Negi A, Jain V. Sternal cleft repair: A report of two cases and review of literature. Afr J Paediatr Surg. 2010;7(3):211-3. doi: 10.4103/0189-6725.70432. [PubMed: 20859036].

8. Ishikawa N, Hiranuma C, Sato H, Ueno Y, Seki M, Yamamoto M. Congenital sternal cleft with patent ductus arteriosus: Report of a case. Surg Today. 2002;32(1):66-8. [PubMed: 11871821]. 